\title{
The Role of Vocabulary Breadth and Depth on Reading Comprehension in Grade 1-4
}

\author{
Hyojin Yoon ${ }^{\mathrm{a}}$, Soyeong Pae ${ }^{\mathrm{b}}$, Bhu Ja Chung ${ }^{\mathrm{a}}$ \\ ${ }^{a}$ Department of Speech-Language Pathology, Chosun University, Gwangju, Korea \\ ${ }^{b}$ Division of Speech pathology and Audiology, Hallym University, Chuncheon, Korea
}

\author{
Correspondence: Soyeong Pae, PhD \\ Division of Speech Pathology and Audiology, \\ Audiology and Speech Pathology Research \\ Institute, Hallym University, 1 Hallimdaehak-gil, \\ Chuncheon 24252, Korea \\ Tel: $+82-33-248-2214$ \\ Fax: +82-33-256-3420 \\ E-mail: spae@hallym.ac.kr
}

Received: April 25, 2018

Revised: May 22, 2018

Accepted: May 22, 2018

This work was supported by research fund from Chosun University, 2016.
Objectives: The purpose of this study was to explore the role of vocabulary breadth and depth in reading comprehension. Specifically, the study examined which vocabulary knowledge (including receptive vocabulary, word associations and definitions) would influence on reading comprehension. Methods: Forty-three children in grades 1-2 and 51 children in grades 3-4 participated in the study. All children obtained 70 or higher on the nonverbal intelligence test. All participants were administered two reading comprehension tasks, and three vocabulary tests including receptive vocabulary, word associations, and word definitions. Because different reading comprehension formats would have different components affecting the contribution of reading comprehension, an open-ended question format and cloze task format were used. Stepwise multiple regressions were conducted to determine which vocabulary knowledge explained the two reading comprehension scores. Results: In grades 1 and 2, word association and definition accounted for the unique variances in each reading comprehension task. In grades 3 and 4, definition explained the variance in each comprehension task. Receptive vocabulary accounted for additional variance only on cloze-format reading comprehension. Conclusion: The results of the study were consistent with previous studies which suggested vocabulary knowledge would be an important key for text comprehension. Specifically, depth of vocabulary is more important for reading comprehension than depth breadth of vocabulary.

Keywords: Reading comprehension, Vocabulary breadth, Vocabulary depth, Receptive vocabulary, Word association, Definition
텍스트를 읽고 이해한다는 것은 텍스트 내에 있는 단어와 문장 을 이해하고, 텍스트 내에 없는 정보는 문맥을 통해 추론을 하고, 독자가 가지고 있는 배경지식을 통합하여 텍스트에서 묘사하고 있 는 전반적인 상황에 대한 심적 표상(mental representation)을 구축 하는 것이다(Kintsch \& Rawson, 2007). Kintsch (1998)와 Kintsch 와 Rawson (2007)은 상황 모델(situation model)과 구성-통합 모델 (construction-integration model)을 바탕으로 이러한 심적 표상의 과정을 분석하였다. 심적 표상을 위해서는 여러 단계에서 복잡한 인지 및 언어 처리 과정을 거쳐야 하는데 첫 단계에서는 단어를 해 독하고, 단어의 의미를 파악하고 구문을 분석함으로써 문장을 이 해해야 한다. 두 번째 단계에서는 독자가 자신의 이해 정도를 모니 터링하고 추론을 통해 텍스트의 전반적인 의미를 분석해야 한다.
이해의 마지막 단계에서는 텍스트를 읽는 독자의 목적을 고려하면 서 텍스트와 관련한 독자의 배경지식을 통합하여 내용에 대한 심 적 표상을 구성하게 된다. 이처럼 독자는 단순한 수준의 처리에서 시작하여 상위로 갈수록 점차 복잡한 처리 과정을 거치면서 텍스 트를 이해할 수 있게 된다.

독자가 효과적인 심적 표상을 구성하기 위해서는 일차적으로 어 휘지식이 중요하다. 이는 어휘지식이 텍스트의 의미를 파악하기 위 한 중요한 단서가 되기 때문이다. 심적 표상의 첫 단계에서처럼 독 자가 텍스트를 이해하려면 포함된 어휘들의 의미를 활발하게 활성 화해야 하는데, 그러기 위해서는 우선 어휘지식이 양적으로 풍부해 야 한다. 일반적으로 독자는 텍스트에 포함된 어휘의 약 $90 \%$ 정도 를 알아야 의미를 정확하게 파악할 수 있다고 한다(Nagy \& Scott, 
2000). 나머지 $10 \%$ 는 텍스트의 문맥을 통해 추론을 함으로써 이해 할 수 있을 것이다. 어휘지식이란 단어의 이름과 개념 정도를 아는 피상적 수준을 넘어 동의어나 반의어, 범주어 등과 같이 어휘의 의 미자질에 대한 정교한 지식을 의미하며, 텍스트를 응집력 있는 내 용으로 이해하기 위해 관련 없는 어휘 정보는 비활성화해야 하는 과정도 포함한다. 더 나아가 사전적 정의에 대한 지식까지 심도 있 게 알고 있을 때 효과적인 이해가 가능하다. 이러한 어휘지식은 양 적인 측면(breadth)과 깊이의 측면(depth)으로 구분하여 살펴볼 수 있는데, 단어의 이름과 개념을 아는 정도를 어휘지식의 양적 측면 이라고 한다면, 각 단어의 개념과 관련된 다른 단어들을 알고, 단어 의 정의까지 아는 정도를 어휘지식의 깊이에 관한 측면이라고 할 수 있다(Oakhill, Cain, \& Elbro, 2015; Ouellette, 2006). 특히, 선행 연구에서는 심적 표상을 구축하기 위해서 어휘의 양뿐 아니라 어 휘를 깊게 아는 지식 또한 중요하게 고려되어야 할 측면이라고 지적 하고 있다(Oakhill et al., 2015).

Nagy와 Scott (2000)은 어휘지식이란 “전부 아니면 아무것도 아 닌 것(all or nothing)"이 아니라고 설명한 바 있다. 즉, 한 개인이 가 지고 있는 각 단어에 대한 지식에는 일종의 정도(degree)가 있어, 어 떤 단어는 이름만 알고 있는 정도인 반면, 어떤 단어는 그 단어와 관 계된 다양한 지식을 가지고 있고, 사전적 정의를 할 수 있을 만큼 깊 게 알 수도 있다는 것이다. 특히, Nagy와 Scott (2000)은 어휘습득 을 점증성(incrementality)으로 설명하고자 하였다. 영유아 시기의 초기 어휘습득 과정에서는 빠른연결(quick mapping)을 통해 의미 를 정확하게 알지 못하더라도 자신의 어휘집에 일단 저장을 하지만 점차 지속적으로 노출되면서 의미가 정교화되는 확장연결(extended mapping)을 통해 어휘지식을 깊게 쌓아간다는 것이다(Carey, 2010). 다시 말하면, 초기 어휘를 습득하는 과정에서는 양적 증가가 활발하게 일어나게 되고, 점차 각 단어와 관련한 의미자질들을 정 교화하면서 질적인 향상을 보인다고 설명할 수 있다.

Oakhill 등(2015)은 어휘지식에 대한 깊이를 6단계로 나누어 설 명하였다. 1 단계와 2 단계는 피상적 수준의 이해단계로 '전에 들어 본 적이 있거나 어휘에 대해 약간 알고 있다', 3 단계는 '사전적 정의 나 구체적으로 설명은 어렵지만 문장의 예시 등을 통해 그 어휘가 어떻게 사용되는지 알고 있다', 4단계는 '범주어휘를 안다', 5 단계는 '어휘의 동의어나 반의어 등을 제시하여 설명할 수 있다' 마지막 단 계인 6단계는 사전적 정의를 제시할 수 있다'이다. 이 단계에 따르 면 1-2단계는 어휘의 양과 관련된 양적 측면이다. 4-6단계는 어휘의 깊이와 관련된 측면으로 간주할 수 있다. 어휘의 양적인 측면은 개 별적인 단어의 이름을 알고 표면적인 의미속성을 아는 정도이다.

이런 어휘지식의 깊이의 수준에 따라 어휘 평가방식은 다양하
다. 또한 앞에서도 언급했듯이 어휘지식은 안다/모른다로 이분법적 으로 나눌 수는 없지만, 앞에서 분류한 것처럼 대부분의 연구자들 은 다음과 같은 방식으로 양적인 측면과 깊이적인 측면을 평가하 는 데 동의하는 것으로 보인다. 우선 양적인 측면에 대한 측정은 각 개인이 얼마나 많은 단어를 보유하고 있는 지를 평가하는 것이다. 단어의 이름대기와 같은 표현어휘검사(expressive vocabulary task) 나 단어를 이해를 하고 있는지를 살펴보기 위해 여러 그림 중 검사 자가 말한 단어를 적절하게 선택할 수 있는지를 보는 수용어휘검 사(receptive vocabulary task)를 통해서 한다. 어휘의 깊이를 살펴 보는 측면은 일반적으로 동의어나 반의어, 상위·하위 범주어 산출, 그리고 정의하기 산출을 통해 측정한다(Nation \& Cocksey, 2009; Ouellette, 2006; Ouellette \& Shaw, 2014; Tannenbaum, Torgesen, \&Wagner, 2006).

어휘능력은 읽기이해와 관련성이 높은 변인일 뿐 아니라 읽기이 해를 지속적으로 예측하는 유의한 변인 중 하나이다(Cain \& Oakhill, 2011; McKeown, Beck, Omanson, \& Perfetti, 1983; Yoon, 2015). 어휘능력과 읽기이해는 일방적인 인과관계가 아니라 서로 영향을 주고받는 관계로 보고 있다(Cunningham, 2005; Seigneuric \& Ehrlich, 2005). 읽기습득의 초기 단계에서 단어를 재인할 때에도 어휘 지식은 중요하다. 단어를 재인하기 위해서는 단어의 음운적 정보뿐 아니라 의미적 정보도 통합되어야 하기 때문이다. 점차 글을 유창 하게 읽게 되면 그때부터는 텍스트가 새로운 어휘습득을 돕는 통 로가 된다(Cunningham, 2005; Nagy \& Scott, 2000). 어휘능력과 읽기발달의 관계는 선순환만 있는 것이 아니라 악순환도 있을 수 있다. 마태효과(Matthew effect)는 이러한 선순환과 악순환의 관계 를 설명한다. 제한된 어휘지식을 가진 아동을 읽고 이해하는 데 어 렵고, 이러한 경험이 읽기에 대한 기대와 동기를 상실하게 하며 읽 기경험의 부족을 야기한다. 결국 읽기경험 부족은 텍스트로부터 새로운 어휘를 습득하는 데 제한을 두게 된다(Stanovich, 1986).

어휘의 양적인 측면과 깊이의 측면 중 읽기이해와 관련이 더 높 은 어휘지식이 무엇인지에 대한 연구결과는 일관되지 않는다. 일부 연구에서는 수용어휘와 표현어휘 등 어휘의 양적 측면보다는 어휘 의 의미에 대한 부담이 좀 더 높은 정의하기 능력이 읽기이해와 더 높은 관련성을 가진다고 보고하였다(Cain \& Oakhill, 2014; Ouellette, 2006). Ouellette (2006)은 초등 4학년을 대상으로 하여 여러 어휘지식이 읽기이해에 미치는 설명력을 살펴보았다. 연구에서 우 선적으로 연령, 비구어성지능, 단어읽기 능력을 투입 후 어휘점수 를 순차적으로 투입하여 위계적 회귀분석을 실시하였다. 수용어휘 점수, 표현어휘, 정의하기가 차례로 투입되었을 때는 수용어휘는 $6 \%$, 정의하기도 $8 \%$ 의 유의한 설명력이 부가적으로 나타났다. 다음 
단계에서는 표현어휘, 수용어휘, 정의하기 순으로 투입되었고, 이 때는 표현어휘 설명력이 $4 \%$, 정의하기도 여전히 $8 \%$ 유의하게 설명 력이 있는 것으로 나타났다. 반면 정의하기가 1 차적으로 투입이 되 었을 때에는 $12 \%$ 의 설명력이 있는 것으로 나타났으나 수용어휘와 표현어휘의 설명력은 유의하지 않은 것으로 나타났다. 하지만 일부 다른 연구에서는 어휘의 양적인 측면이 읽기이해와 더 높은 관련성 을 보이거나 어휘지식의 양적 측면이 우선적으로 투입된 후에는 깊 이 측면은 더 이상 설명력을 보이지 않는 것으로 나타나기도 했다 (Ouellette \& Shaw, 2014; Tannenbaum et al., 2006). 이처럼 읽기이 해에 미치는 어휘의 어휘의 양적 측면과 질적 측면이 다르게 나타 난 것은 대상아동의 연령, 어휘지식 평가방식, 더 나아가 읽기이해 검사 형식의 차이에 기인한 것으로 해석할 수 있다.

본 연구는 초등 1-4학년의 읽기이해를 설명하는 어휘지식을 양 적인 측면과 깊이의 측면에서 살펴보고자 하였다. 선행연구들에 따 르면 읽기이해검사 형식에 따라 영향을 미치는 변인들이 달라지는 것으로 나타나(Chung, Kim, \& Yoon, 2017; Cutting \& Scarborough, 2006; Keenan, Betjemann, \& Olson, 2008) 본 연구에서는 짧은 지 문을 읽은 후 대답하는 문답형식의 읽기이해검사와 1 문장에서 6 문장의 짧은 글을 읽고 빈 칸에 적절한 답을 채우는 빈칸 채우기 형 식의 읽기이해검사를 실시하고 두 읽기이해 점수를 종속변인으로 설정하여 분석을 실시하고자 하였다. 어휘지식의 양적인 측면은 수 용·표현어휘력검사(Receptive and Expressive Vocabulary Test, REVT; Kim, Hong, Kim, Jang, \& Lee, 2009)의 수용어휘검사를 통 해 측정하였으며, 깊이 측면은 Korea Institute for Special Education-Basic Academic Achievement Test (KISE-BAAT; Park, Kim, Song, Jung, \& Jung, 2008)의 낱말이해와 연구자가 개발한 정의하 기 검사를 통해 측정하였다. 본 연구는 단어해독능력이 빠르게 발 달하는 1-2학년과 단어해독이 정확하고 유창해지면서 점차 새로 운 학습을 위한 읽기로 전환이 되는 3-4학년 두 집단으로 나누어 읽기이해에 대한 어휘지식의 설명력을 살펴보고자 하였다.

\section{연구방법}

\section{연구대상}

본 연구는 광주광역시에 소재한 초등학교 1-4학년에서 각 학년 당 1 개반의 모든 아동이 연구에 참여하였다. 검사의 시기는 각 학 년 말인 12월에 실시하였다. 연구에 참여한 아동의 선정기준은 (1) 학급 교사에 의해 발달이 정상적으로 이루어진다고 보고된 아동 으로 특수교육대상자로 선정되지 않은 아동이며, (2) 감각, 인지, 신 경학적인 문제가 없다고 보고된 아동으로, (3) 한국 비언어지능검
사 2판(Korean version of Comprehensive Test of Nonverbal Intelligence second edition; Park, 2014)의 검사 결과 70점 초과인 아동 이다. 최초로 연구에 참여한 아동은 97 명이었으며, 모든 검사를 완 료하지 못한 아동과 비언어성지능검사 결과 70점 이하인 아동은 본 연구의 분석에서 제외하여 최종적으로 94 명의 검사 결과가 분 석대상에 해당하였다.

Chall (1983)의 읽기단계에 따르면, 초등 1-2학년 시기는 단어를 해독하는 능력을 습득하고 발달시켜 나가는 단계이다. 초등 3-4학 년 시기는 이미 습득한 해독능력을 토대로 하여 정확하고 유창하 게 글을 읽으며, 학습을 위한 읽기단계로 넘어가는 단계이다. 그러 므로 본 연구에서는 읽기이해능력에 미치는 어휘능력의 설명력을 살펴보기 위해 초등 1-2학년 집단과 초등 3-4학년 집단으로 나누어 살펴보고자하였다.

연구대상자의 정보는 Table 1 과 같다.

\section{검사도구}

본 연구에서는 초등학교 1-4학년의 읽기이해능력과 어휘지식을 측정하였다. 읽기이해는 KISE-BAAT 기초학력검사(Park et al., 2008) 의 짧은 글 이해와 한국어읽기검사(Korean Language based Reading Assessment, KOLRA: Pae, Kim, Yoon, \& Jang, 2015)의 읽기이 해를 사용하여 측정하였다. KISE-BAAT의 짧은 글 읽기검사는 짧 은 지문을 읽고 주요 사실, 사실과 의견, 비유나 상징, 글의 주제, 결 과 유추와 비판 등과 관련한 질문에 대답하는 문답과제 형식이며, 총 30 문항이다. KOLRA의 읽기이해검사는 1 문장에서 6 문장으로 이루어진 문장과 짧은 문단글을 읽고 빈칸에 채우는 형식이며, 총 24 개의 문항으로 구성되었다.

어휘능력은 어휘의 양적 측면과 깊이 측면으로 나누어 측정하였 다. 양적 측면으로는 수용·표현어휘력검사(REVT; Kim et al., 2009) 의 수용어휘를 평가하였다. 깊이 측면으로는 어휘관계와 정의하기 능력을 평가하였다. 어휘관계는 KISE-BAAT의 낱말이해검사를 통

Table 1. Participants' characteristics

\begin{tabular}{lccc}
\hline & \multicolumn{2}{c}{ Gender } & \multirow{2}{*}{ CTONI-2 } \\
\cline { 2 - 3 } & Male & Female & \\
\hline Grade 1 $(\mathrm{N}=22)$ & 9 & 13 & $105.64(9.50)$ \\
Grade 2 $(\mathrm{N}=21)$ & 12 & 9 & $103.90(11.26)$ \\
Grade 3 $(\mathrm{N}=25)$ & 13 & 12 & $103.80(20.44)$ \\
Grade 4 $(\mathrm{N}=26)$ & 14 & 12 & $102.38(13.19)$ \\
Total & 48 & 46 & $103.86(14.27)$ \\
\hline
\end{tabular}

Values are presented as mean (SD).

CTONI-2 = Korean Comprehensive Test of Nonverbal Intelligence second edition (Park, 2014). 
해 측정하였다. KISE-BAAT의 낱말이해검사는 주어진 단어를 읽 은 후 지시에 따라 관련된 단어를 산출하는 검사이다. 포함된 문항 은 반의어(예: 출발-‘도착', 5 문항), 동의어(예: 다투다-싸우다', 5 문 항), 존대어와 관련한 동의어(예: 나이-'연세', 2 문항), 유추를 통한 범주관계(예: 구두/운동화/등산화-'신발', 4 문항), 어휘 유추(예: 아 침-'점심'-저녁, 2문항), 수량단위(예: 배추 두 ‘포기', 2문항)를 묻는 문항으로 구성되어 있으며, 총 20 개의 문항이다. 정의하기 평가는 저자가 개발중인 단어 정의하기 과제를 사용하여 평가하였다. 정의 하기 과제는 총 20 개의 명사로, 구체명사 10 개(예: 고드름, 태양 등) 와 추상명사 10 개(예: 실망, 칭찬 등)로 구성되었다. 검사자는 아동 에게 '이제부터 단어와 그 단어가 들어간 문장을 잘 들으세요. 그리 고 그 단어의 뜻을 말해주면 됩니다라는 지시문을 제공하였다. 목 표 단어가 포함된 문장의 예는 '동생은 저 고드름을 갖고 싶어'등과 같다. 아동이 제시된 단어의 정의를 적절하게 표현하였을 때 1 점 (예: 물이 아래로 흐르다가 얼은 것)으로 채점하였다. 아동이 단어 의 정의를 적절하게 표현하지 못한 경우와 그 단어를 사용하여 문 장을 표현한 경우(예: 저기 고드름이 차가웠다 등), 그리고 무반응 인 경우는 0 점 처리하였다. 정의하기 과제의 내용타당도는 언어병 리학 박사학위를 가진 언어병리학교수 3 인과 언어재활사 1 급 자격 증을 소지하고 10 년 이상의 임상경력을 가진 2 인에게 의뢰하였다. 내용타당도 지수는 5 점 척도로 하였으며, 1 점은 '매우 타당하지 않 다', 2점은 ‘타당하지 않다’, 3점은 ‘보통이다', 4점은 ‘타당하다', 5 점 은 '매우 타당하다'로 구성하였다. 과제의 내용타당도는 4.78 의 타 당도를 얻었다.

\section{연구절차}

검사는 아동이 다니는 초등학교의 도서관, 과학실과 빈 교실에 서 진행하였다. 검사는 검사자가 아동과 일대일로 실시하였다. 검 사는 검사실시 교육을 받은 언어병리학을 전공하는 대학원생이 실 시하였다. 각 검사자들은 검사의 신뢰도를 높이기 위해 충분히 검 사의 내용과 실시방법에 대한 사전교육을 받았다. 각 아동당 검사 시간은 약 1 시간에서 1 시간 30 분 정도 소요되었다.

\section{통계분석}

읽기이해, 어휘검사 모두 원점수로 통계분석을 실시하였다. 우선 연구변인인 읽기이해, 수용어휘, 어휘관계, 정의하기 간의 관계를 보기 위해 피어슨 적률상관관계 분석을 실시하였다. 읽기이해에 대 한 여러 어휘지식의 설명력을 살펴보기 위해 단계적 다중회귀분석 (stepwise multiple regression)을 실시하였다. KISE-BAAT의 읽기 이해와 KOLRA의 읽기이해검사를 종속변인으로 하였으며, 읽기 능력을 예측하는 독립변인으로 수용어휘, 어휘관계, 정의하기 점수 를 투입하였다. 통계분석에는 SPSS Statistics version 21 을 사용하였다.

\section{연구결과}

읽기이해, 수용어휘, 어휘관계, 정의하기 변인 점수에 대한 기술통 계와상관분석을 실시하였으며, 그 결과는 Tables 2 와 3 에 제시하였다.

상관분석 결과 초등 1-2학년에서는 KISE-BAAT 읽기이해와 KOLRA 읽기이해 점수 모두 수용어휘, 어휘관계, 정의하기 점수와

Table 3. Correlations between reading comprehension, RV, WA, and word definition scores

\begin{tabular}{clccccc}
\hline & & PC & RC & RV & WA & Definition \\
\hline Grade 1-2 & PC & - & & & & \\
& RC & $.651^{* * *}$ & - & & & \\
& RV & $.546^{* * *}$ & $.553^{* * *}$ & - & & \\
& WA & $.646^{* * *}$ & $.586^{* * *}$ & $.583^{* * *}$ & - & \\
& Definition & $.591^{* * *}$ & $.648^{* *}$ & $.496^{* *}$ & $.400^{*}$ & - \\
Grade 3-4 & PC & - & & & & \\
& RC & $.317^{*}$ & - & & & \\
& RV & $.320^{*}$ & $.429^{* *}$ & - & & \\
& WA & .252 & .260 & $.349^{*}$ & - & \\
& Definition & $.329^{*}$ & $.451^{* *}$ & $.383^{* *}$ & $.417^{* *}$ & - \\
\hline
\end{tabular}

$\mathrm{PC}=$ passage comprehension of KISE-BAAT (Korea Institute for Special EducationBasic Academic Achievement Test; Park, Kim, Song, Jung, \& Jung, 2008); RC= reading comprehension of KOLRA (Korean Language based Reading Assessment; Pae, Kim, Yoon, \& Jang, 2015); RV = receptive vocabulary of REVT (Receptive and Expressive Vocabulary Test; Kim, Hong, Kim, Jang, \& Lee, 2009); WA=word association of KISE-BAAT; Definition = word definition.

${ }^{*} p<.05,{ }^{* *} p<.01,{ }^{* * *} p<.001$.

Table 2. Descriptive statistics for reading comprehension, RV, WA, and word definition scores of children in grades 1-2 and grades 3-4

\begin{tabular}{lrrrrr}
\hline & PC & RC & RV & WA & Definition \\
\hline Grade 1-2 $(\mathrm{N}=43)$ & $8.21(5.31)$ & $9.76(4.22)$ & $90.74(16.32)$ & $10.33(4.05)$ & $4.71(1.92)$ \\
Grade 3-4 $(\mathrm{N}=51)$ & $15.82(5.44)$ & $15.06(3.99)$ & $118.16(17.35)$ & $14.75(2.60)$ & $6.95(1.97)$ \\
\hline
\end{tabular}

$\mathrm{PC}=$ passage comprehension of KISE-BAAT (Korea Institute for Special Education-Basic Academic Achievement Test; Park, Kim, Song, Jung, \& Jung, 2008); RC= reading comprehension of KOLRA (Korean Language based Reading Assessment; Pae, Kim, Yoon, \& Jang, 2015); RV= receptive vocabulary of REVT (Receptive and Expressive Vocabulary Test; Kim, Hong, Kim, Jang, \& Lee, 2009); WA= word association of KISE-BAAT; Definition= word definition. 
Table 4. Stepwise regression analysis of reading comprehension tasks using RV, WA, and word definition scores

\begin{tabular}{|c|c|c|c|c|c|c|}
\hline & & B & $\beta$ & $\mathrm{R}^{2}$ & $\Delta \mathrm{R}^{2}$ & $F$ \\
\hline \multirow[t]{2}{*}{ PC for grade $1-2$} & WA & .633 & .456 & .384 & $.384^{* * *}$ & $20.938^{* * *}$ \\
\hline & Definition & 1.123 & .409 & .524 & $.141^{* *}$ & \\
\hline \multirow[t]{2}{*}{$\mathrm{RC}$ for grade $1-2$} & Definition & 1.090 & .504 & .419 & $.419^{* * *}$ & $21.192^{* * *}$ \\
\hline & WA & .397 & .368 & .534 & $.115^{* *}$ & \\
\hline PC for grade 3-4 & Definition & .907 & .329 & .108 & $.108^{*}$ & $5.928^{*}$ \\
\hline \multirow[t]{2}{*}{$\mathrm{RC}$ for grade $3-4$} & Definition & .683 & .332 & .203 & $.203^{* *}$ & $9.010^{* * *}$ \\
\hline & RV & .068 & .297 & .277 & $.074^{*}$ & \\
\hline
\end{tabular}

$\mathrm{PC}=$ passage comprehension of KISE-BAAT (Korea Institute for Special Education-Basic Academic Achievement Test; Park, Kim, Song, Jung, \& Jung, 2008); RC=reading comprehension of KOLRA (Korean Language based Reading Assessment; Pae, Kim, Yoon, \& Jang, 2015); RV= receptive vocabulary of REVT (Receptive and Expressive Vocabulary Test; Kim, Hong, Kim, Jang, \& Lee, 2009); WA= word association of KISE-BAAT; Definition= word definition.

${ }^{*} p<.05,{ }^{* *} p<.01,{ }^{* * *} p<.001$.

정적 상관을 보이는 것으로 나타났다 $(r=.400-651)$. 반면, 초등 3-4 학년에서는 두 이해검사 모두 수용어휘, 정의하기와만 정적 상관관 계를 보이는 것으로 나타났다. 어휘관계는 경향성은 나타났으나 ( $p=.068-.074)$, 유의한 상관관계는 없는 것으로 나타났다. 두 집단 모두 두 읽기이해검사 간에, 그리고 세 어휘검사 간에는 모두 유의 하게 정적 상관을 보이는 것으로 나타났다.

읽기이해를 설명하는 어휘변인을 살펴보기 위해 회귀분석을 실시 하였으며, 그에 따른 결과는 Table 4에 제시하였다. 각 학년 집단별로 나누어 회귀분석을 실시하였다. 두 읽기이해 점수를 종속변수로 설 정하였으며, 수용어휘, 어휘관계, 정의하기를 독립변인으로 설정하여 단계적 다중회귀분석을 실시하였다. 읽기이해를 설명하는 어휘 변인 을 살펴보기 위한 회귀모형 모두 VIF가 1.267-2.143으로 나타나 다중 공선성은 발생하지 않는 것으로 나타났다. 또한 Durbin-Watson은 1.972-2.341로 나타나잔차간에자기상관은 없는 것으로 나타났다.

우선 초등 1-2학년에서 KNISE-BAAT의 짧은 문단글을 읽고 대 답하는 문답과제 형식 읽기이해는 어휘관계가 $38.4 \%$ 를 설명하고 정 의하기가 $14.1 \%$ 를 부가적으로 설명하는 것으로 나타났다. 1-6문장 을 읽고 빈칸에 적절한 어휘나문법형태소 등을 넣는 빈칸 채우기 형 식의 KOLRA 읽기이해는 정의하기가 $41.9 \%$ 를 설명하고 어휘관계가 $11.5 \%$ 를 부가적으로 유의하게 설명하는 변인인 것으로 나타났다. 초 등 3-4학년에서는 KISE-BAAT 읽기이해는 정의하기만이 $10.8 \%$ 로 설명력이 있는 변인으로 나타났다. KOLRA의 읽기이해는 정의하기 가 $20.3 \%$ 로 가장 설명력이 있는 변인이며, 뒤를 이어 수용어휘가 $7.4 \%$ 로 부가적으로 유의하게 설명력 있는 변인으로 나타났다.

초등 1-2학년과 3-4학년 모두 정의하기가 읽기이해를 설명하는 유의한 변인으로 일관되게 나타났다. 1-2학년에서는 또한 어휘관계가 설명력 있는 변인으로 나타났다. 반면 수용어휘는 3-4학년 KOL$\mathrm{RA}$ 읽기이해에서만 정의하기의 뒤를 이어 부가적으로 설명하는 변 인으로 나타났다.

\section{논의 및 결론}

본 연구는 초등 1-2학년과 초등 3-4학년의 읽기이해능력에 영향을 미치는 어휘지식을 살펴보고자 하였다. 특히, 어휘지식을 양(breadth) 와 깊이(depth)로 나누어 읽기이해에 미치는 영향력을 살펴보고자 하였다. 이에 읽기이해를 평가하는 형식에 따라 예측하는 변인이 다르게 나타난다는 연구결과에 근거하여(Chung et al., 2017; Cutting \& Scarborough, 2006; Keenan et al., 2008) 짧은 지문을 읽은 후 대답하는 문답형식과 1-6개의 문장을 읽고 빈 칸을 적절하게 채 우는 빈칸 채우기의 두 읽기이해검사를 실시하여 그 결과를 종속 변인으로 설정하였다.

연구결과 초등 1-2학년에서는 두 읽기이해 점수 모두가 세 가지 어휘검사, 즉 수용어휘, 어휘관계, 정의하기 점수와 유의한 정적 상 관관계를 보이는 것으로 나타났다. 반면, 3-4학년 집단에서의 읽기 이해는 수용어휘 및 정의하기와 상관관계가 나타났으나, 어휘관계 와는 두 읽기이해 점수 모두 경향성만 있을 뿐 유의한 상관관계는 없는 것으로 나타났다. 선행연구들에서도 학령기 아동의 읽기이해 능력과 어휘능력 간의 강력한 상관성을 일관적으로 보고하고 있다 (Oakhill et al., 2015; Protopapas, Sideridis, Mousaki, \& Simos, 2007). 본 연구에서 나타난 상관관계는 텍스트를 읽은 후 텍스트에서 묘 사하는 상황에 대한 적절한 심적 표상을 구상하는 데에 어휘 의미 지식은 없어서는 안될 중요한 요소라는 것을 뒷받침하는 결과라고 할수 있다(Nagy \& Scott, 2000).

읽기이해에 미치는 세 어휘지식의 영향력을 살펴보기 위해 단계 적 회귀분석을 실시한 결과 초등 1-2학년에서는 어휘의 깊이를 측 정한 어휘관계와 정의하기가 두 읽기이해를 모두 예측하는 유의한 설명력 있는 변인으로 나타났다. 구체적으로 살펴보면, KISE -BAAT 의 문답형식의 읽기이해에서는 어휘관계가 $38.4 \%$ 의 설명력이 있는 것으로 나타났으며, 그 뒤를 이어 정의하기 점수가 $14.1 \%$ 를 부가적 
으로 설명력이 있는 변인으로 나타났다. KORLA의 빈칸 채우기 읽 기이해검사에서는 정의하기가 $41.9 \%$ 로 가장 설명력이 큰 변인이었 으며, 뒤를 이어 어휘관계가 $11.5 \%$ 부가적으로 설명하는 변인으로 나타났다. 반면 어휘의 양적인 측면을 나타내는 수용어휘는 두 읽 기검사 모두에서 유의한 설명력을 가진 변인은 아닌 것으로 나타났 다. 초등 3-4학년에서는 두 읽기이해검사 모두에서 일관적으로 정 의하기가 유의한 예측변인으로 나타났다. KISE-BAAT의 읽기이해 검사에서는 정의하기가 $10.8 \%$ 의 설명력을 가졌으며, KOLRA의 읽 기이해검사에서는 정의하기가 $20.3 \%$ 로 가장 큰 설명력을 보였고, 뒤를 이어 수용어휘가 $7.4 \%$ 를 부가적으로 설명하는 변인으로 나타 났다. 종합하면 영향력의 크기와 순서에는 차이가 있었지만 1-2학 년과 3-4학년 모두에서 정의하기가 일관적으로 설명력 있는 변인 으로 나타났으며, 1-2학년 집단에서는 어휘관계도 읽기이해를 예 측하는 변인으로 나타났다. 수용어휘는 3-4학년의 KOLRA 읽기이 해에서만 정의하기에 이어 부가적인 설명력을 갖는 변인으로 나타 났다. 결국 어휘의 깊이와 관련된 지식이 일관되게 두 학년 집단 모 두에서 읽기이해를 설명하는 중요한 변인으로 나타났다고 해석할 수 있다.

흥미로운 부분은 초등 1-2학년에서는 두 검사 모두에서 비교적 깊은 수준의 어휘지식을 측정한 어휘관계와 정의하기가 설명력이 있는 것으로 나타났을 뿐 아니라 정의하기는 3-4학년의 읽기이해검 사 2 개 모두에서 가장 설명력 있는 변인으로 나타났다는 점이다. 이 러한 결과는 단어의 표면적인 의미만을 단순히 아는 지식보다 좀 더 깊은 수준에서 어휘지식을 갖고 있는 것, 즉 단어의 개념, 단어들 간의 관계를 아는 지식이 읽은 내용을 효과적으로 이해하는 데 더 도움을 준다는 해석을 가능하게 한다. 정의하기 과제는 일반적으 로 어휘의 깊이를 측정하는 어휘지식 평가과제로 사용되었다(Cain \& Oakhill, 2014; Ouellette, 2006). 읽기이해를 예측하는 요인을 살 펴본 선행연구에서도 주어진 단어의 의미를 파악하고, 적절한 문 맥 내에서 사용할 수 있을 뿐 아니라 사전적 정의를 할 수 있는 능력 인 정의하기는 수용어휘를 넘어, 혹은 수용어휘보다 더 설명력이 있는 변인으로 보고되었다(Cain \& Oakhill, 2014; Ouellette, 2006). 읽기이해를 설명하는 어휘지식을 살펴본 대표적인 연구인 Ouellette (2006)의 연구에서도 연령과 비구어성지능, 해독능력을 통제 한 후에도 가장 설명력이 높은 변인으로 나타나 읽기이해에 대한 정의하기의 설명력과 중요성이 드러났다.

텍스트를 읽고 전반적인 응집성 추론(global coherence inference) 질문과 지엽적인 응집성 추론(local coherence inference)질문에 대 답하는 능력과 어휘지식 간의 관계를 살펴본 Cain과 Oakhill (2014) 의 연구에서도 정의하기 등, 깊은 수준의 어휘지식이 전반적인 응
집성 추론과 상관관계가 더 높을 뿐 아니라 설명력도 더 높은 것으 로 나타났다. 읽기이해는 담화에 대한 이해로, 담화는 하나의 주제 나 사건을 중심으로 응집력 있는 구성이 되어야 한다. KISE-BAAT 의 읽기이해 문항은 중심내용 파악, 생략된 내용 추론, 의도 파악, 연결된 내용 추론 등 전반적인 응집성 추론을 할 수 있는지를 묻는 문항들로 구성되어 있다. 따라서 이러한 추론과 통합을 위해서는 정의하기와 같은 깊은 수준의 어휘지식이 필수적이라고 해석할 수 있다. 3-4학년에서 KOLRA 읽기이해의 평균점수는 15점으로 나타 났다. 초반 문항들이 문맥의 구문과 문법형태소적인 측면에 대한 지식이 좀 더 관여된 문항이었다면 중반에서 후반 문항들은 사자 성어 등 어휘지식이 필요한 문항들이 많이 포함되어 있다. 즉, 어휘 의 의미를 표면적으로 이해해서는 응답하기 어려운 사자성어와 같 은 어휘문항들이 제시되면서 좀 더 깊은 수준의 어휘지식에 관한 필요성을 반영했다고 볼 수 있다. 따라서 어휘지식의 깊이가 깊을 수록 텍스트 내의 개별어휘를 활발하게 활성화하여 효과적인 읽기 이해를 가능하게 한다고 설명할 수 있을 것이다. 때때로 어휘가 다 양한 의미를 가지고 있을 때는 텍스트 문맥을 통해 응집성을 갖출 수 있는 어휘만 활성화하고, 나머지 의미들을 억제해야 하는 경우 도 있다. 그러므로 제한된 깊이의 어휘지식이나 어휘에 접근하는 과정의 비효율성은 텍스트를 적절하게 이해하는 데 어려움을 야기 할 수밖에 없을 것이다(Beck, Perfetti, \& McKeown, 1982).

본 연구에서 사용한 어휘관계는 KISE-BAAT의 낱말이해검사로 제시된 단어를 읽고 동의어, 반의어, 상위·하위 범주어, 유추, 존대 어와 관련한 동의어 등을 표현하는 과제이다. 여러 단어 간의 관계 는 의미관계(semantic relation), 범주화(categorization), 동의어나 반의어 등의 관계로 나누어 살펴볼 수 있으며, 이런 관계 내에서 어 휘들은 서로 간에 높은 상호관련성을 갖는다. 이러한 관계는 어휘의미 체계(lexical-semantic system)로 설명할 수 있는데(Ouellette \& Shaw, 2014; Ursino, Cuppini, \& Magosso, 2010), 어휘관계 과제는 아동들이 각 어휘 개념 간의 관계에 대한 지식이 있을 때 해결할 수 있는 과제이기 때문이다. 이러한 과제를 해결하려면 개별적인 단어 의 이름을 말하거나 단어를 재인하는 수준을 넘어선 비교적 깊은 수준의 단어에 대한 이해가 필요하다. 따라서 단어들 간의 관련성 에 대한 지식을 묻는 과제는 각 개인이 가지고 있는 의미조직(semantic organization)의 깊이를 반영한다고 해석할 수 있다. 어휘관 계를 살펴본 연구들은 주어진 단어와 관련된 동의어나 반의어 산 출, 혹은 보기 중 선택하는 과제로 측정하고자 하였다. 어휘관계가 비교적 표면적 수준에서의 어휘지식을 측정한다고 볼 수도 있지만 대체적으로는 주어진 단어와의 관련성, 즉 단어가 가지는 의미자 질을 확인하고 그러한 자질과 관련된 다른 단어를 선택하는 과정 
들이 필요하기 때문에 깊은 수준의 어휘지식을 측정한다고 할 수 있다(Oakhill et al., 2015; Ouellette, 2006). 어휘관계와 읽기이해와 의 관련성을 살펴본 연구들도 두 능력 간의 깊은 관련성을 설명하 였으며, 어휘관계가 읽기이해를 예측하는 변인이라는 결과를 보고 하였다(Kim \& Hwang, 2008; Leider, Proctor, Silversman, \& Harring, 2013; Nation \& Snowling, 2004; Proctor, Uccelli, Dalton, \& Snow, 2009). Yim (2013) 또한 동의어나 반의어, 범주어 등의 어휘 의미(lexical semantic relation)는 텍스트의 응집성을 만들어내는 데 중요한 장치라고 설명하였다. 이는 텍스트에서는 결속장치라고 불리는 어휘들 간의 관계가 담화의 응집성을 구성하기 때문에 어 휘들 간의 관계에 대한 지식이 부족하다면 담화의 사실적 정보와 추론적 정보를 파악하고 글의 맥락과 자신의 배경지식을 통합하여 전체적인 응집력 있는 글로 이해하는 데 어려움이 있을 것임을 시 사하는 설명이다. 특히, 읽기이해검사에서의 많은 질문들이 텍스트 를 한 문장으로 요약하거나 글의 주제를 찾는 등 통합하는 과제이 기 때문에 어휘관계에 대한 지식의 부족은 이해의 어려움을 야기 할 수 있다. KISE-BAAT의 읽기이해검사는 짧은 지문을 읽은 후 질 문에 대답하는 형식이며, 질문내용은 앞 문항들은 사실적 정보를 이해했는지를 묻는다면 중반에서 후반 문항은 주제나 중심내용 파악하고, 텍스트에 기반하여 추론을 할 수 있는지를 묻는 문항이 다. 위에서 언급했듯이 이러한 검사문항을 응집력 있는 내용으로 통합하는 데 어휘관계를 파악하는 지식이 중요하기 때문에 어휘관 계의 설명력이 높게 나타난 것으로 해석할 수 있다. KOLRA의 읽기 이해검사는 1-6문장의 짧은 문장과 문단글을 읽고, 문맥에 적절한 어휘나 문법형태소, 접속사 등을 빈 칸에 넣는 검사이다. 주어진 텍 스트가 짧기 때문에 긴 텍스트처럼 유추하거나 통합하여 얻을 수 있는 정보가 적다. 그렇기 때문에 더더욱 문장 내의 중요 단어를 파 악하고, 그 중요 단어의 의미와 그 단어와 관련된 어휘들에 대한 지 식이 중요하다고 볼수 있다.

읽기이해는 추론과 예측을 포함한 높은 수준의 인지 및 언어 처 리 과정을 필요로 한다. 단어해독능력이 자동화되는 시기가 되면 어휘지식의 양과 깊이가 점차 중요해진다(Protopapas et al., 2007). 효과적인 읽기이해를 위해서는 개별적인 어휘의 의미를 확인하고 개념을 연상하는 등의 피상적 수준 이상의 어휘지식이 필요하다. 어휘들 간의 관계인 어휘-의미 체계가 잘 조직화 되어 있어야 하며, 사전적 정의의 수준까지 알고 있을 때 효율적으로 의미가 활성화된 다. 이는 읽기이해에 필요한 정교한 어휘의 의미자질에 대한 지식의 소유가 중요하다는 것을 의미한다. 어휘지식의 정도가 텍스트 의미 에 대한 표상의 수준을 결정한다(Cain \& Oakhill, 2014; Ouellette, 2006). 따라서 문맥 내의 중요 단어에 대한 지식이 충분할 때 의미
를 구성하기가 쉽다. 즉, 독자는 텍스트 내의 중요 단어에 대한 충분 한 지식이 있을 때 충분한 심적 표상을 빠르게 구축할 수 있다. 반 면 관련 어휘지식이 충분하지 않을 때는 텍스트가 표현하고자 하 는 심적 표상을 활성화하는 데 어렵고, 이는 정보를 통합하거나 추 론하는 데 어려움을 야기할 수밖에 없다. 상황모델로 설명한다면 어휘지식이 문장과 담화를 이해하는 데 필수적인 단어를 파악하 고 응집력 있는 글로 통합하여 텍스트가 묘사하는 상황에 대한 표 상을 활발하게 활성화한다고 설명할 수 있다.

앞에서도 언급했듯이 어휘지식은 “전부 혹은 아무것도 없는 것" 이 아니다. 깊이라고 말하는 일종의 연속성(continuum)이 있다고 말할 수 있다. 어휘지식에 대한 단계적 차이를 깊이에 대한 평가라 고 할 수 있을 것이다(Vermeer, 2001). 본 연구에서 세 어휘지식을 평가하였지만 이 세 가지 어휘지식을 평가하는 데 관여한 능력이 독립적이라고 볼 수는 없다. 세 어휘지식의 차이와 관련성 등을 좀 더 자세히 파악하고 읽기이해와의 관련성을 살펴보는 후속연구가 필요할 것이다. 또한 어휘의 양 자체가 적은 언어학습부진 아동이 나 학습장애 아동의 경우 어휘의 양과 깊이가 어떤 영향을 미치는 지에 대한 후속연구도 필요할 것이다. 본 연구결과는 학령기 아동 의 읽기평가와 중재에서 얼마나 어휘를 많이 아는지에 대한 양적인 측면뿐 아니라 어휘지식의 깊이와 같은 질적인 측면도 고려해야 한 다는 근거를 제공할 수 있을 것이다.

\section{REFERENCES}

Beck, I., Perfetti, C., \& McKeown, M. (1982). Effects of long-term vocabulary instruction on lexical access and reading comprehension. Journal of Educational Psychology, 74, 506-521.

Cain, K., \& Oakhill, J. (2011). Matthew effects in young readers: Reading comprehension and reading experience aid vocabulary development. Journal of Learning Disabilities, 44, 431-443.

Cain, K., \& Oakhill, J. (2014). Reading comprehension and vocabulary: is vocabulary more important for some aspects of comprehension? L’Année Psychologique, 114, 647-662.

Carey, S. (2010). Beyond fast mapping. Language Learning and Development, 6, 184-205.

Chall, J. (1983). Learning to read: the great debate. New York. NY: McGraw-Hill.

Chung, B., Kim, Y., \& Yoon, H. (2017). Relative contribution of components to different reading comprehension tasks in grade 3-4. Communication Sciences and Disorders, 22, 66-75.

Cunningham, A. E. (2005). Vocabulary growth through independent read- 
ing and reading aloud to children. In E. H. Hiebert \& M. L. Kamhi (Eds.), Teaching and learning vocabulary: bringing research to practice (pp. 45-68). Mahwah, NJ: Lawrence Erlbaum Associates.

Cutting, L., \& Scarborough, H. (2006). Prediction of reading comprehension: relative contributions of word recognition, language proficiency, and other cognitive skills can depend on how comprehension is measured. Scientific Studies of Reading, 10, 277-299.

Keenan, J. Betjemann, R., \& Olson, R. (2008). Reading comprehension tests vary in the skills they assess: differential dependence on decoding and oral comprehension. Scientific Studies of Reading, 12, 281-300.

Kim, A., \& Hwang, M. (2008). Prediction of reading skills in upper elementary students. Korean Journal of Communication Disorders, 13, 1-25.

Kim, Y. T., Hong, G. H., Kim, G. H., Jang, H. S., \& Lee, J. Y. (2009). Receptive and Expressive Vocabulary Test (REVT). Seoul: Seoul Community Rehabilitation Center.

Kintsch, W. (1998). Comprehension: a paradigm for cognition. New York: Cambridge University Press.

Kintsch, W., \& Rawson, K. (2007). Comprehension. In M. J. Snowling \& C. Hulme (Eds.), The science of reading: a handbook (pp. 211-226). Oxford: Blackwell Publishing.

Leider, C., Proctor, R., Silversman, R., \& Harring, J. (2013). Examing the role of vocabulary depth, cross-linguistic transfer, and types of reading measures on the reading comprehension of Latino bilinguals in elementary school. Reading and Writing, 26, 1459-1485.

McKeown, M., Beck, I., Omanson, R., \& Perfetti, C. (1983). The effects of long-term vocabulary instruction on reading comprehension: a replication. Journal of Reading Behavior, 15, 3-18.

Nagy, W. \& Scott, J. (2000). Vocabulary process. In M. Kamil et al. (Eds.), Handbook of reading research Volume III (pp. 269-284). Muhwah, NJ: Lawrence Erlbaum Associates.

Nation, K., \& Cocksey, J. (2009). The relationship between knowing a word and reading it aloud in children's word reading development. Journal of Experimental Child Psychology, 103, 296-308.

Nation, K., \& Snowling, M. (2004). Beyond phonological skills: Broader language skills contribute to the development of reading. Journal of Research in Reading, 27, 342-356.

Oakhill, J., Cain, K., \& Elbro, C. (2015). Understanding and teaching reading comprehension. New York, NY: Routledge.
Ouellette, G. P. (2006). What's meaning got to do with it: the role of vocabulary in word reading and reading comprehension. Journal of Educational Psychology, 98, 554-566.

Ouellette, G., \& Shaw, E. (2014). Oral vocabulary and reading comprehension: an intricate affair. L’Année Psychologique, 114, 623-645.

Pae, S., Kim, M., Yoon, H. J., \& Jang, S. (2015). Korean Language based Reading Assessment (KOLRA). Seoul: Hakjisa.

Park, G., Kim, G., Song, Y., Jung, D., \& Jung, I. (2008). Korea Institute for Special Education-Basic Academic Achievement Test (KISE-BAAT). Ansan; Korea Institute for Special Education.

Park, H. (2014). Korean version of Comprehensive Test of Nonverbal Intelligence second edition (K-CTONI-2). Seoul: Mindpress.

Proctor, C. P., Uccelli, P., Dalton, B., \& Snow, C. E. (2009). Understanding depth of vocabulary online with bilingual and monolingual children. Reading \& Writing Quarterly, 25, 311-333.

Protopapas, A., Sideridis, G. D., Mouzaki, A., \& Simos, P. G. (2007). Development of lexical mediation in the relation between reading comprehension and word reading skills in Greek. Scientific Studies of Reading, 11, 165-197.

Seigneuric, A., \& Ehrlich, M. F. (2005). Contribution of working memory capacity to children's reading comprehension: a longitudinal investigation. Reading and Writing, 18, 617-656.

Stanovich, K. E. (1986). Matthew effects in reading: some consequences of individual differences in the acquisition of literacy. Reading Research Quarterly, 21, 360-407.

Tannenbaum, K. R., Torgesen, J. K., \& Wagner, R. K. (2006). Relationships between word knowledge and reading comprehension in third-grade children. Scientific Studies of Reading, 10, 381-398.

Ursino, M., Cuppini, C., \& Magosso, E. (2010). A computational model of the lexical-semantic system based on a grounded cognition approach. Frontiers in Psychology, 1, 221.

Vermeer, A. (2001). Breadth and depth of vocabulary in relation to L1/L2 acquisition and frequency of input. Applied Psycholinguistics, 22, 217-234.

Yim, C. (2013). Lexical semantic relation and lexical cohesion. Korean Semantics, 40, 307-321.

Yoon, H. J. (2015). Prediction of reading comprehension in early and late elementary grades: contribution of word decoding, vocabulary and syntactic knowledge. Communication Sciences \& Disorders, 20, 536-546. 


\section{국문초록}

\section{초등 1-4학년 아동의 읽기이해능력에서 어휘지식의 양과 깊이의 역할 \\ 윤효진 ${ }^{1} \cdot$ 배소영 ${ }^{2}$ 정부자 ${ }^{1}$ \\ '조선대학교 언어치료학과, ${ }^{2}$ 한림대학교 언어청각학부}

배경 및 목적: 본 연구는 초등 1-4학년의 읽기이해를 설명하는 어휘지식을 다양한 측면에서 살펴보고자 하였다. 어휘지식의 양적 측면 은 수용어휘, 깊이적 측면은 어휘관계와 정의하기를 측정하여 각 어휘지식이 읽기이해에 미치는 영향을 보았다. 방법: 초등 1-2학년 43 명과 초등 3-4학년 51명으로 총 94명이 본 연구에 참여하였다. 연구에 참여한 모든 아동의 비구어성 지능지수는 70점 이상이었다. 읽기 이해검사 형식에 따라 영향을 미치는 관련 변인이 달라진다는 선행연구결과에 근거하여 문답형식과 빈칸 채우기 형식의 두 읽기이해검 사를 실시하여 종속변인으로 설정하였다. 읽기이해를 예측하는 독립변인은 수용어휘, 어휘관계, 정의하기의 세 가지 어휘지식으로 하 여 단계적 회귀분석을 실시하였다. 결과: 첫째, $1-2$ 학년에서는 두 읽기이해검사 모두에서 정의하기와 어휘관계가 설명력이 있는 어휘지 식 변인으로 나타났다. 둘째, 3-4학년에서는 짧은 지문을 읽은 후 대답하는 문답형식의 읽기이해검사에서는 정의하기가, 빈칸 채우기 형식의 읽기이해검사에서는 정의하기와 수용어휘가 설명력이 있는 변인으로 나타났다. 논의 및 결론: 전반적으로 두 집단 모두에서 정 의하기, 어휘관계와 같은 어휘지식의 깊이 측면이 읽기이해에 영향을 미치는 것으로 나타났다. 어휘지식의 깊이가 깊을수록 텍스트 내 의 개별어휘를 활발하게 활성화하여 효과적인 읽기이해를 가능하게 한다고 설명할 수 있을 것이다

핵심어: 읽기이해, 어휘의 양, 어휘의 깊이, 수용어휘, 어휘관계, 정의하기

본 논문은 2016학년도 조선대학교 학술연구비의 지원을 받아 연구되었음.

\section{참고문헌}

김애화, 황민아 (2008). 초등학교 고학년의 읽기능력에 영향을 미치는 읽기관련변인에 관한 연구. 언어청각장애연구, 13, 1-25.

김영태, 홍경훈, 김경희, 장혜성, 이주연(2009). 수용·표현어휘력검사(REVT). 서울: 서울장애인종합복지관.

박경숙, 김계옥, 송영준, 정동영, 정인숙(2008). 기초학력검사(Korea Institute for Special Education-Basic Academic Achievement Test, KISE-

BAAT). 안산: 국립특수교육원.

박혜원(2014). 한국 비언어지능검사 2판(K-CTONI-2). 서울: 마인드프레스.

배소영, 김미배, 윤효진, 장승민(2015). 한국어 읽기검사(KOLRA). 서울: 학지사.

윤효진(2015). 초등 저학년과 고학년의 읽기이해 예측 요인 연구. 언어청각장애연구, 20, 536-546.

임채훈(2013). 어휘의미 관계와 어휘적 응집성. 한국어 의미학, 40,307-321.

정부자, 김영태, 윤효진 (2017). 읽기이해검사의 형식에 다른 관련 요인 탐색: 초등학교 3-4학년을 대상으로. 언어청각장애연구, 22, 66-75. 